\title{
12 Die Steuerung des Energieumsatzes im Gehirn
}

\author{
(C) Springer-Verlag GmbH Deutschland, ein Teil von Springer Nature 2018 \\ D. Mathias, Fit und gesund von 1 bis Hundert \\ https://doi.org/10.1007/978-3-662-56307-6_12
}

Die Regulation des Energieumsatzes durch Hunger und Sättigung wird im Gehirn gesteuert. Der Hypothalamus, ein Teil des Zwischenhirns, spielt bei diesem überaus komplexen Vorgang die dominierende Rolle (Nguyen et al. 2011; Nakajima et al. 2016). Die Hormone Neuropeptid Y (NPY) und Agouti-related-Protein (AGRP) stimulieren den Appetit und drosseln den Energieverbrauch im Grundumsatz. Gegenspieler von NPY und AGRP sind das a-Melanozyten stimulierende Hormon (a-MSH) sowie das "cocaine- and amphetamineregulated transscript «(CART). Beide dämpfen den Appetit und erhöhen den Energieverbrauch. NPY/AGRP wirken also auf den Appetit wie ein Gaspedal und $\alpha-M S H / C A R T$ wie eine Bremse.

Diese Systeme hemmen sich zunächst gegenseitig. Als Regulativ dafür dient ein normaler Glucosespiegel. Sinkende Glucosekonzentrationen bei fehlender Nahrungsaufnahme heben aber die hemmende Wirkung der $\alpha$-MSH/CART-Zellgruppe auf. Das in seiner Funktion jetzt überwiegende NPY/ AGRP-System stimuliert die Bildung der Orexine A und $\mathbf{B}$, die im lateralen Hypothalamus Hungergefühle auslösen. Zusätzlich aktivieren diese die Wachfunktion des Gehirns, denn schließlich muss man munter sein, um Nahrung zu sich nehmen zu wollen oder, wie in früheren Zeiten unabdingbar, um auf Nahrungssuche gehen zu können. Nach Sättigung verdrängen die jetzt in höherer Konzentration vorhandenen Glucosemoleküle die Orexine von ihren Rezeptoren. Der Appetit lässt nach, der Mensch wird müde und kann besser einschlafen.

Tückisch aber ist in diesem Zusammenhang der heute selbst schon von Jugendlichen übertriebene Konsum von reinem Zucker, z. B. durch das Viel- trinken von Softdrinks ( $\triangleright$ Kap. 50). Denn unser normaler Kristallzucker besteht nur zur Hälfte aus Glucose. Die andere Hälfte ist Fructose. Dieser Fruchtzucker liefert genauso viele Kalorien wie die Glucose, greift jedoch nicht bremsend in die Steuerungssignale des Energieumsatzes ein ( $\triangleright$ Kap. 14). Deshalb führen diese Süßgetränke zu einer besonders schnellen Körperfettbildung bei (Caprio 2012; de Ruyter et al. 2012; Te Morenga et al. 2013; Page et al. 2013).

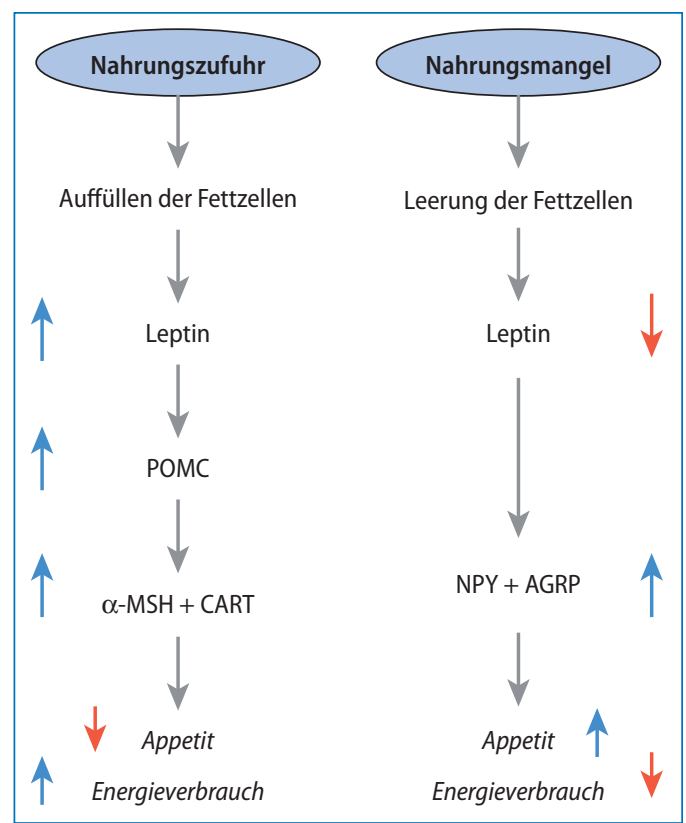

- Abb. 12.1 Regulation von Appetit und Energieverbrauch. POMC Proopiomelanocortin, roter Pfeil Verminderung, blauer Pfeil Erhöhung 